\title{
FINANCIAL VARIABLES AND THE OUT-OF-SAMPLE FORECASTABILITY OF THE GROWTH RATE OF INDIAN INDUSTRIAL PRODUCTION
}

\author{
Rangan GUPTA, Yuxiang YE, Christopher M. SAKO \\ Department of Economics, University of Pretoria, 0002 Pretoria, South Africa
}

Received 14 April 2012; accepted 04 August 2012

\begin{abstract}
In this paper, we consider the forecasting power, both in- and out-of-sample, of 11 financial variables with respect to the growth rate of Indian industrial production over the monthly out-ofsample period of 2005:4-2011:4, using an in-sample of 1994:1-2005:3. The financial variables used are: $\mathrm{M} 0, \mathrm{M1}, \mathrm{M} 2, \mathrm{M} 3$, lending rate, 3-month Treasury bill rate, term spread, real effective exchange rate, real stock prices, dividend yield and non-food credit growth. We observe that that, at times, in-sample and out-of-sample predictive ability of the financial variables tend to coincide. We find relatively strong evidence of out-of-sample predictability for at least one of the horizons for M0, M1, M2, M3, the lending rate and real share price growth rate. The term-spread and dividend yield are added to the list when weaker versions of the out-of-sample test statistics are considered as well. Given that we consider a large number of financial variables, when we checked the significant results by accounting for data mining across the 11 financial variables, majority of these results ceases to be significant, with only $\mathrm{M} 0, \mathrm{M} 1$ and $\mathrm{M} 2$ retaining some of its predictive ability.
\end{abstract}

Keywords: financial variables, forecastability, forecast encompassing, industrial production, India.

Reference to this paper should be made as follows: Gupta, R.; Ye, Y.; Sako, C. M. 2013. Financial variables and the out-of-sample forecastability of the growth rate of Indian industrial production, Technological and Economic Development of Economy 19(Supplement 1): S83-S99.

JEL Classification: C22, C53, E44, E32.

Corresponding author Rangan Gupta

E-mail: Rangan.Gupta@up.oc.za 


\section{Introduction}

There exists a large international literature dealing with the role of financial variables in forecasting real output growth ${ }^{1}$. However, as far as India is concerned, there is virtually no studies dealing with this issue. The four papers, distantly related to this topic that we could come across are the recent works by Ray and Chatterjee (2001), Biswas et al. (2010), Kar and Mandal (2011) and Bhattacharya et al. (2011). Biswas et al. (2010), used a three-variable Bayesian vector autoregressive (BVAR) model, comprising of industrial production, whole sale price index and M1, to forecast inflation and industrial production growth. They showed that the BVAR model outperformed its classical counterpart in forecasting both inflation and output growth, but the study did not emphasize the role M1 plays in the forecasting performance of the two key macro variables. While Ray and Chatterjee (2001) indicated financial variables (stock price inflation, broad money (M3) growth rate, call money rate, gold price inflation and exchange rate) did not Granger-cause gross domestic product (GDP) growth ${ }^{2}$, Kar and Mandal (2011) indicated that non-food credit and stock prices did Granger-cause the growth rate of industrial production. Bhattacharya et al. (2011) used financial variables, such as deposits, non-food credit growth and the national stock exchange turnover, in their bridge-equation ${ }^{3}$ for now casting the GDP. In general, as can be seen, the little evidence, at times conflicting, that exists regarding the role of financial variables in forecasting Indian output growth is mainly in-sample. And as is well-known, it is possible for a variable to carry significant in-sample information even when it is not the case out-of-sample (Rapach et al. 2005; Rapach, Wohar 2006). Also, Beck et al. $(2000,2004)$ points out that, forecasting is at the root of inference in time series analysis. Further, as argued by Clements and Hendry (1998), in time series models, estimation and inference essentially means minimizing of the one-step (or multi-step) forecast errors. Hence, establishing a model superiority boils down to showing that it produces smaller forecast errors than its competitors. In other words, one needs to analyse whether adding financial variables over and above the information already contained in the lagged output growth improves predictability of the latter over an outof-sample, besides within-sample.

Against this backdrop, we consider the forecasting power of 11 financial variables with respect to the growth rate of Indian industrial production over the monthly outof-sample period of 2005:4-2011:4, using an in-sample of 1994:1-2005:3. The length of our entire sample period is governed by data availability, while, the starting point of the out-of-sample period is motivated by the fact that the growth rate of the Indian industrial production became more volatile ever since, as can be seen from Figure 1. Note that, we use industrial production as a measure of output rather than the GDP, simply because of the fact that quarterly values of the latter are only available from the beginning of 1994 . Given this, we felt that around seventy data points covering eighteen years (1994-2011)

\footnotetext{
Refer to Stock and Watson (2003) and, more recently, Rossi and Sekhposyan (2010) and Espinoza et al. (2012), for a detailed literature review in this regard.

2 The study found that barring the gold price inflation and the exchange rate, the three other financial variables Granger-caused commodity price inflation.

3 A bridge equation is generally designed to "bridge" early releases of monthly indicators with quarterly GDP.
} 

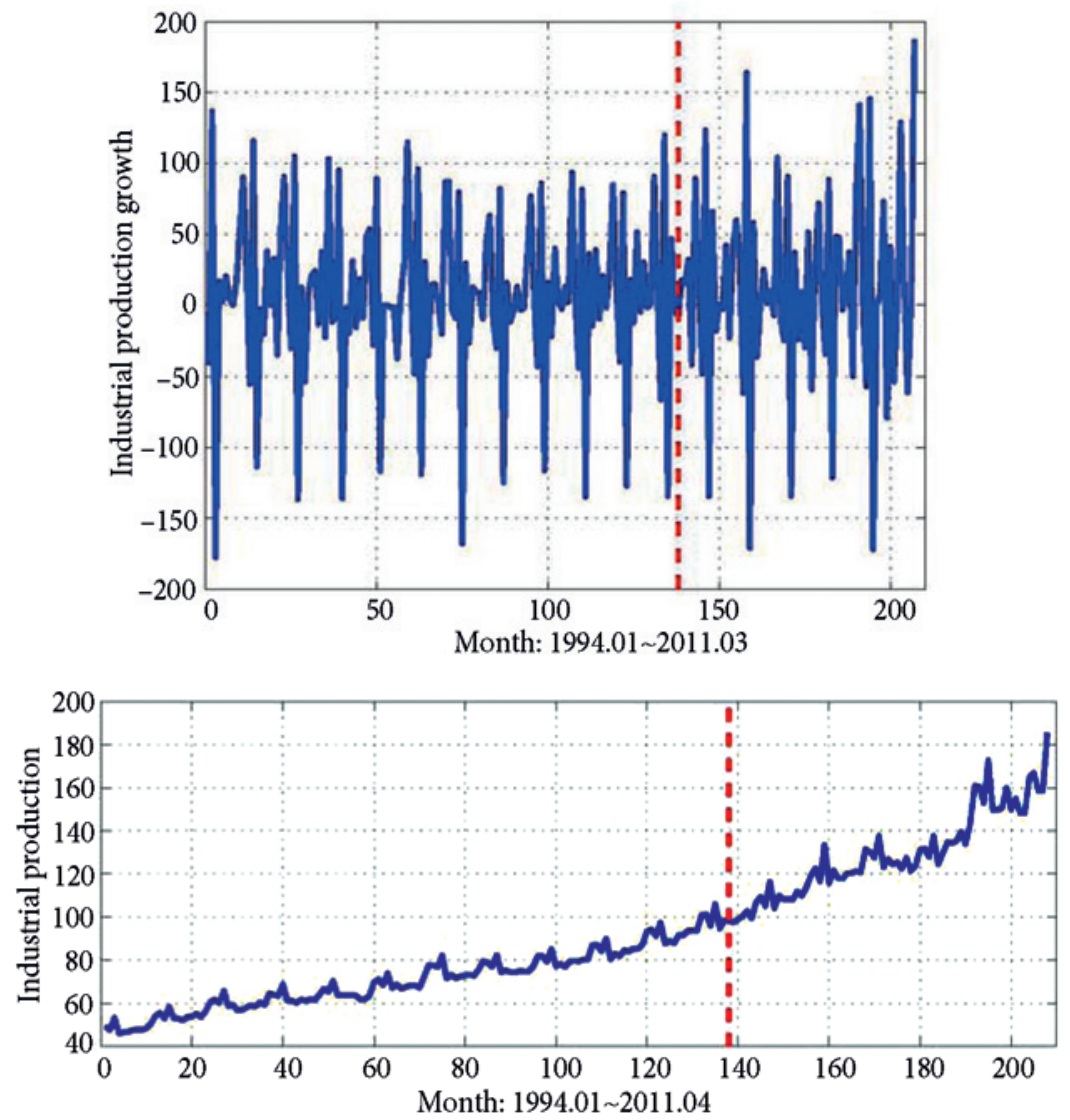

Fig. 1. Industrial production in levels and growth rates

or so, would be too small a sample to yield statistically significant results, and hence, fail to yield credibility to our analysis. Further, even in the current scenario where services are undertaking an increasing weight in economies around the world, forecasting the industrial production index is an important task for short-term economic analysis. In fact, because some of the services activities (such as business services) are closely linked to the industrial ones, the industrial sector is still important in explaining aggregate fluctuations. In addition, forecasts of industrial production can be useful in more general forecasting models. For example, Bhattacharya et al. (2011), use the industrial production index in the bridge-equation for forecasting the quarterly Indian GDP. In this case, reliable threemonth ahead forecasts would be extremely helpful. Furthermore, the industrial production index series could be used to derive cyclical indicators of the manufacturing sectors, which, in turn, requires signal extraction techniques, and, hence, accurate forecasts of the industrial production that needs to be filtered are essential ${ }^{4}$.

$4 \quad$ See Bruno and Lupi (2004) for further details regarding the importance of forecasting industrial production. 
The 11 financial variables used in this study, namely, M0, M1, M2, M3, lending rate, 3-month Treasury bill rate, term spread, real effective exchange rate, real stock prices, dividend yield and non-food credit growth, are quite popular in the extant literature (Rapach, Weber 2004). For each financial variable, we construct recursive out-of-sample forecasts of industrial production growth over the 2005:4-2011:4 period based on an autoregressive distributed lag (ARDL) model that includes a given financial variable as an explanatory variable. We use the Harvey et al. (1998) and Clark and McCracken (2001) statistics to test the null hypothesis that the out-of-sample forecasts of industrial production growth from a benchmark autoregressive (AR) model encompass the forecasts from the ARDL model that includes a given financial variable. To understand better the idea of forecast encompassing, consider two sets of out-of-sample forecasts of the industrial production: one from an ARDL model that includes a financial variable and one from the benchmark AR model, and consider forming an optimal composite forecast as a convex combination of the forecasts from the two models. If the optimal weight attached to the forecast from the ARDL model is greater than zero (equal to zero), then the ARDL model does (does not) contain information that is useful for forecasting the output growth apart from the information already contained in the AR model. Clark and McCracken $(2001,2005)$ indicates that there are a number of econometric issues that arise when comparing forecasts from two nested models, as is obviously the scenario in our applications. Hence, following the recommendations of Clark and McCracken (2005), we base our inferences on a bootstrap procedure similar to the one in Kilian (1999). Furthermore, given that we consider a large number of financial variables, we check the robustness of our results using a version of the Inoue and Kilian (2005) bootstrap procedure that explicitly controls for data mining. The rest of the article is organized as follows: We lay out the basics of the approaches used to testing for forecasting ability in Section 1. Section 2 presents that data, and discusses forecasting test results. In this section, we also check whether the significant results can be attributed to data mining. The final section contains concluding remarks.

\section{Econometric methodology}

Let us define: $\Delta y_{t}=y_{t}-y_{t-1}$, where $y_{t}$ is the log-level of industrial production at time $t$. Also let $z_{t+h}=\sum_{i=1}^{h} \Delta y_{t+i}$. Given this, the ARDL model can be defined as follows:

$$
z_{t+h}=\alpha+\sum_{i=0}^{q_{1}-1} \beta_{i} \Delta y_{t-i}+\sum_{i=0}^{q_{2}-1} \gamma_{i} \Delta x_{t-i}+\varepsilon_{t+h},
$$

with $h$, the forecasting horizon; $x_{t}$, the financial variable and $\varepsilon_{t+h}$, the disturbance term. As the $z_{t+h}$ observations will be overlapping in this case, the disturbance term is serially correlated when $h>1$. To account for the serial correlation in the disturbance term, a Newey and West (1987) - type heteroscedasticity and autocorrelation-consistent (HAC) covariance matrix is be used. Although we are primarily interested in out-of-sample tests, it is straightforward to conduct an in-sample test of the forecasting ability of $x_{t}$ by using all of the available ob- 
servations to conduct a Wald test of the null hypothesis that $\gamma_{0}=\ldots=\gamma_{q_{2}-1}=0$. If we reject this null hypothesis, this is evidence that the financial variable $x_{t}$ has in-sample forecasting ability with respect to future output growth.

To assess the simulated out-of-sample forecasting ability of a given financial variable with respect to output growth, we use a recursive scheme. This allows us to simulate the situation of a forecaster in real time. We divide the total sample of $T$ observations into an in-sample (first $R$ observations) and an out-of-sample (remaining $P$ observations). We compute outof-sample forecasts from the unrestricted version of equation (1) and also from a restricted version that excludes the financial variable (Eq. (1) with $\gamma_{0}=\ldots=\gamma_{q_{2}-1}=0$ ). Our recursive scheme continuously updates the parameter estimates of the models by adding one observation at a time from the out-of-sample to the expanding in-sample, and forecasting $h$-steps ahead. This results in two sets of $T-R-h+1$ recursive out-of-sample forecast errors, one each for the unrestricted and restricted regression models $\left(\left\{\hat{u}_{1, t+h}\right\}_{t=R}^{T-h}\right.$ and $\left\{\hat{u}_{0, t+h}\right\}_{t=R}^{T-h}$, respectively $)^{5}$.

The next step is to compare the simulated out-of-sample forecasts from the unrestricted and restricted models. And we do this by using the Theil's $U$ metric, which, in turn, is defined as the ratio of the root mean squared forecast error (RMSFE) for the unrestricted model forecasts to the RMSFE for the restricted model forecasts. So, if the RMSFE for the unrestricted model forecasts is less (more) than the RMSFE for the restricted model forecasts, then $U<(>) 1$. To test whether the MSFE for the unrestricted model forecasts is statistically less than the MSFE for the restricted model forecasts, we use the Diebold and Mariano (1995) and West (1996) statistic, as well as a variant of this statistic due to McCracken (2004). Both statistics are based on the loss differential: $\hat{d}_{t+h}=\hat{u}_{0, t+h}^{2}-\hat{u}_{1, t+h}^{2}$. Let $\bar{d}=(T-R-h+1)^{-1} \sum_{t=R}^{T-h} \hat{d}_{t+h}=\widehat{M S F E_{0}}-\widehat{M S F E_{1}}$ and $\hat{S}_{d d}=\sum_{j=-J}^{J} K(j / J) \hat{\Gamma}_{d d}(j)$, where $\widehat{M S F E_{1}}=(T-R-h+1)^{-1} \sum_{t=R}^{T-h} \hat{u}_{i, t+h}^{2}(i=0,1)$, $\hat{\Gamma}_{d d}(j)=(T-R-h+1)^{-1} \sum_{t=R+j}^{T-h}\left(\hat{d}_{t+h}-\bar{d}\right)\left(\hat{d}_{t+h-j}-\bar{d}\right)$, and $\hat{\Gamma}_{d d}(-j)=\hat{\Gamma}_{d d}(j)$, the Diebold and Mariano (1995) and West (1996) statistic can be expressed as:

$$
M S E-T=(T-R-h+1)^{0.5} \cdot \bar{d} \cdot \hat{S}_{d d}^{-0.5} .
$$

Under the null hypothesis of equal forecasting ability, $M S F E_{0}=M S F E_{1}$, so that $\bar{d}$ and $M S E-T$ are equal to zero. We test this null hypothesis against the one-sided (upper-tail) alternative hypothesis that the MSFE for the unrestricted model forecasts is less than the MSFE for the restricted model forecasts $\left(M S F E_{0}>M S F E_{1}\right)$, so that $M S E-T>0$. We follow Clark and McCracken (2005) and use the Bartlett kernel, $K(j / J)=1-[j /(J+1)]$, and we set $J=[1.5 h]$ for $h>1$, where [ $\bullet]$ is the nearest-integer function; for $h=1$, we use $\hat{S}_{d d}=\hat{\Gamma}_{d d}(0)$. The McCracken(2004) variant of the MSE-T statistic is given by:

$$
M S E-F=(T-R-k+1) \cdot \bar{d} / \widehat{M S F E_{1}} .
$$

For further details, refer to Rapach and Weber (2004). 
An alternative way to judge forecasting ability is based on the notion of forecast encompassing. Consider forming an optimal composite out-of-sample forecast of $z_{t+h}$ as a convex combination of the out-of-sample forecasts from the unrestricted and restricted models:

$$
\hat{z}_{c, t+h}=\lambda \hat{z}_{1, t+h}+(1-\lambda) \hat{z}_{0, t+h}
$$

where $0 \leq \lambda \leq 1$. If $\lambda=0(\lambda>0)$, the restricted model forecasts are said to encompass (not encompass) the unrestricted model forecasts, because the latter model does not contribute any valuable information, over and above that is already contained in the restricted model. Harvey et al. (1998) develop a statistic that can be used to test the null hypothesis that $\lambda=0$ in Eq. (4) against the one-sided (upper-tail) alternative hypothesis that $\lambda>0$ :

$$
E N C-T=(T-R-h+1)^{0.5} \cdot \bar{c} \cdot \hat{S}_{c c}^{-0.5}
$$

where: $\hat{c}_{t+h}=\hat{u}_{0, t+h}\left(\hat{u}_{0, t+h}-\hat{u}_{1, t+h}\right), \bar{c}=(T-R-h+1)^{-1} \sum_{t=R}^{T-h} \hat{c}_{t+h}, \hat{S}_{c c}=\sum_{j=-J}^{J} K(j / J) \hat{\Gamma}_{c c}(j)$, $\hat{\Gamma}_{c c}(j)=(T-R-h+1)^{-1} \sum_{t=R+j}^{T-h}\left(\hat{c}_{t+h}-\hat{c}\right)\left(\hat{c}_{t+h-j}-\hat{c}\right)$, and $\hat{\Gamma}_{c c}(-j)=\hat{\Gamma}_{c c}(j)$. We again use $K(j / J)=1-[j /(J+1)], \quad J=[1.5 h]$ for $h>1$, and $\hat{S}_{d d}=\hat{\Gamma}_{d d}(0)$ for $h=1$.

Clark and McCracken (2001) propose a variant of the ENC-T statistic:

$$
E N C-N E W=(T-R-k+1) \cdot \bar{c} / \widehat{M S F E_{1}} .
$$

Clark and McCracken (2001) showed that these four forecast comparison statistics have a non-standard asymptotic distribution for $h=1$. Furthermore, Clark and McCracken (2004) also showed that these statistics have a nonstandard asymptotic distribution and is not asymptotically pivotal for $h>1$, when comparing forecasts from nested models, as is our case. Hence, Clark and McCracken (2004) recommend basing inferences for the MSE-T, MSE-F, ENC-T and ENC-NEW statistics on a bootstrap procedure, given that the statistics are not in general asymptotically pivotal. The bootstrap procedure we employ is similar to the one in Clark and McCracken (2004), which is a version of the Kilian (1999) bootstrap procedure, and is discussed in detail in Rapach and Weber (2004). Based on Monte Carlo simulations, Clark and McCracken $(2001,2004)$ indicate that ENC-NEW is the most powerful statistic, followed by the $E N C$ - $T$, the $M S E-F$ and the $M S E-T$. These rankings suggest that the forecast encompassing statistics, especially ENC-NEW, can have important power advantages over test statistics based on relative MSFE. ${ }^{6}$

6 For further details regarding the intuition of these rankings and the potential gains associated with the ENC-type statistics over the MSE-types, refer to Rapach and Weber (2004). 


\section{Data description and empirical results}

\subsection{Data description}

The monthly data used in this study, covering the period of 1994:1-2011:4, are obtained from the Handbook of Statistics on the Indian economy provided by the Reserve Bank of India (RBI), Global Financial Database (GFD) and International Monetary Fund's (IMF) International Financial Statistics (IFS). As discussed before, we use the industrial production index as a proxy for Indian output, while, 11 financial variables are used as possible predictors of the growth rate of industrial production. Besides, the real non-food credit growth, the financial variables used include four monetary aggregates, three interest rate variables, two stock market variables and the real effective exchange rate. The monetary variables are the monetary base (M0), M1, M2 and M3. The interest rate variables comprise of the lending rate, 3-month Treasury bill rate and the term spread, with the latter calculated as the difference between annualized returns on the long-term government bonds (average maturity of 10 years) and 3-month Treasury bills. The two stock market variables are real stock prices and dividend yield. Note, the real values of the non-food credit and stock prices are obtained by dividing the respective nominal values by the Consumer Price Index $(\mathrm{CPI})^{7}$. Data on industrial production, $\mathrm{M} 0, \mathrm{M} 3$, lending rate, 3 -month Treasury bill yield,10-year government bond yield, dividend yield and real effective exchange rate are drawn from GFD, and M1, M2, and the CPI data are from the IFS, with the non-food credit coming from the RBI. To work with stationary variables, industrial production, the four monetary aggregates, real share price, the real effective exchange rate and the real non-food credit is transformed into growth rates. While the dividend yields, lending rate and the 3 -month Treasury bill rate are measured in first differences ${ }^{8}$. We consider horizons $h=1$, 3, 6, 9 and 12 months over a volatile out-of-sample period of 2005:4-2011:4, using an insample of 1994:1-2005:3. Tables 1 and 2 report the results of the forecasting exercise with the growth rate of industrial production appearing as the dependant variable in Eq. (1). For the out-of-sample period, we use the Schwarz Information Criterion (SIC) and in-sample data to determine the lag structure of Eq. (1). We consider values of $q_{1}$ from zero to twelve, while, we considered values of $q_{2}$ from one to twelve to ensure that the financial variable appears in the unrestricted model.

Table 1. Forecasting test results for the out-of-sample period

\begin{tabular}{|c|c|c|c|c|c|}
\hline Horizon(h) & 1 month & 3 months & 6 months & 9 months & 12 months \\
\hline \multicolumn{6}{|l|}{ M0 growth } \\
\hline$\overline{q_{1}}$ & 11 & 9 & 6 & 3 & 0 \\
\hline$q_{2}$ & 11 & 11 & 11 & 8 & 1 \\
\hline Wald & $105.02(0.00)$ & $70.57(0.00)$ & $26.86(0.00)$ & $35.25(0.00)$ & $0.53(0.65)$ \\
\hline
\end{tabular}

Note that our data sources provide a series for the real effective exchange rate on its own, hence, it was not necessary for us to convert the nominal effective exchange rate to its real counterpart.

8 The stationarity of the variables were tests using standard unit root tests. These results are available upon request from the authors. 
Continued Table 1

\begin{tabular}{|c|c|c|c|c|c|}
\hline Horizon(h) & 1 month & 3 months & 6 months & 9 months & 12 months \\
\hline $\bar{U}$ & 0.89 & 0.90 & 0.99 & 0.99 & 1.00 \\
\hline MSE-T & $1.97(0.01)$ & $0.93(0.06)$ & $0.12(0.22)$ & $0.15(0.24)$ & $-0.19(0.46)$ \\
\hline$M S E-F$ & $18.40(0.00)$ & $16.81(0.00)$ & $1.71(0.01)$ & $1.35(0.03)$ & $-0.08(0.44)$ \\
\hline$E N C-T$ & $3.24(0.00)$ & $1.76(0.05)$ & $0.89(0.13)$ & $0.91(0.15)$ & $-0.03(0.58)$ \\
\hline$E N C-N E W$ & $16.25(0.00)$ & $16.61(0.00)$ & $5.70(0.00)$ & $\mathbf{3 . 8 4}(0.00)$ & $-0.01(0.57)$ \\
\hline \multicolumn{6}{|l|}{ M1 growth } \\
\hline$q_{1}$ & 12 & 12 & 6 & 3 & 1 \\
\hline$q_{2}$ & 1 & 1 & 10 & 7 & 5 \\
\hline Wald & $0.43(0.56)$ & $0.38(0.54)$ & 18.64 $(0.01)$ & $\mathbf{9 . 2 2}(0.02)$ & $7.10(0.04)$ \\
\hline$U$ & 1.01 & 1.01 & 1.05 & 1.09 & 1.14 \\
\hline$M S E-T$ & $-0.44(0.39)$ & $-0.52(0.39)$ & $-0.56(0.48)$ & $-0.89(0.58)$ & $-1.36(0.78)$ \\
\hline$M S E-F$ & $-0.94(0.68)$ & $-0.88(0.75)$ & $-5.85(0.97)$ & $-10.00(0.99)$ & $-14.35(0.99)$ \\
\hline$E N C-T$ & $0.72(0.16)$ & $0.75(0.15)$ & $1.28(0.09)$ & $0.17(0.36)$ & $-0.26(0.48)$ \\
\hline ENC-NEW & $0.71(0.11)$ & $\mathbf{0 . 6 5}(0.07)$ & $6.13(0.00)$ & $\mathbf{0 . 9 3}(0.04)$ & $-1.29(0.98)$ \\
\hline \multicolumn{6}{|l|}{ M2 growth } \\
\hline$q_{1}$ & 12 & 12 & 6 & 3 & 1 \\
\hline$q_{2}$ & 1 & 1 & 1 & 1 & 1 \\
\hline Wald & $\mathbf{8 . 6 2}(0.02)$ & $\mathbf{5 . 4 4}(0.03)$ & $1.65(0.26)$ & $0.34(0.64)$ & $1.58(0.25)$ \\
\hline$U$ & 0.98 & 0.99 & 1.01 & 1.01 & 1.01 \\
\hline$M S E-T$ & $1.76(0.00)$ & $1.97(0.00)$ & $-0.82(0.58)$ & $-1.79(0.90)$ & $-0.96(0.61)$ \\
\hline$M S E-F$ & $2.51(0.01)$ & $1.92(0.01)$ & $-1.18(0.82)$ & $-0.86(0.76)$ & $-1.05(0.81)$ \\
\hline$E N C-T$ & $2.77(0.00)$ & $2.27(0.01)$ & $-0.30(0.52)$ & $-1.24(0.82)$ & $-0.29(0.51)$ \\
\hline ENC-NEW & $2.41(0.01)$ & $1.13(0.04)$ & $-0.21(0.71)$ & $-0.26(0.78)$ & $-0.17(0.67)$ \\
\hline \multicolumn{6}{|l|}{ M3 growth } \\
\hline$q_{1}$ & 12 & 12 & 6 & 3 & 0 \\
\hline$q_{2}$ & 1 & 1 & 1 & 1 & 1 \\
\hline Wald & $5.49(0.06)$ & $3.90(0.09)$ & $0.01(0.94)$ & $0.07(0.78)$ & $0.01(0.94)$ \\
\hline$U$ & 0.99 & 0.98 & 1.01 & 1.00 & 1.00 \\
\hline$M S E-T$ & $\mathbf{0 . 9 6}(0.04)$ & $2.11(0.00)$ & $-1.22(0.75)$ & $-1.38(0.79)$ & $-1.81(0.89)$ \\
\hline$M S E-F$ & $1.63(0.05)$ & $2.55(0.02)$ & $-0.88(0.75)$ & $-0.29(0.46)$ & $-0.58(0.72)$ \\
\hline$E N C-T$ & $\mathbf{1 . 4 6}(0.05)$ & $2.20(0.01)$ & $-1.14(0.81)$ & $-1.22(0.82)$ & $-1.75(0.91)$ \\
\hline ENC-NEW & $1.24(0.08)$ & $1.40(0.05)$ & $-0.40(0.86)$ & $-0.12(0.59)$ & $-0.28(0.82)$ \\
\hline \multicolumn{6}{|c|}{ Lending rate, first difference } \\
\hline$q_{1}$ & 12 & 12 & 6 & 3 & 0 \\
\hline$q_{2}$ & 1 & 1 & 1 & 1 & 1 \\
\hline Wald & $\mathbf{4 . 0 6}(0.10)$ & $2.92(0.18)$ & $2.37(0.27)$ & $\mathbf{4 . 8 7}(0.10)$ & $0.00(0.98)$ \\
\hline$U$ & 1.04 & 1.00 & 1.00 & 0.99 & 1.01 \\
\hline$M S E-T$ & $-1.21(0.73)$ & $-0.33(0.35)$ & $0.53(0.20)$ & $0.75(0.15)$ & $-0.91(0.57)$ \\
\hline$M S E-F$ & $-5.46(0.97)$ & $-0.49(0.54)$ & $0.37(0.18)$ & $\mathbf{0 . 9 5}(0.07)$ & $-1.00(0.76)$ \\
\hline$E N C-T$ & $0.88(0.15)$ & $0.52(0.24)$ & $0.81(0.24)$ & $0.78(0.26)$ & $-0.80(0.67)$ \\
\hline ENC-NEW & $1.19(0.08)$ & $0.60(0.13)$ & $0.30(0.24)$ & $0.52(0.15)$ & $-0.43(0.84)$ \\
\hline \multicolumn{6}{|c|}{ 3-month Treasury bill rate, first difference } \\
\hline$q_{1}$ & 12 & 12 & 6 & 3 & 1 \\
\hline
\end{tabular}


Continued Table 1

\begin{tabular}{|c|c|c|c|c|c|}
\hline Horizon $(\mathrm{h})$ & 1 month & 3 months & 6 months & 9 months & 12 months \\
\hline$q_{2}$ & 1 & 1 & 1 & 1 & 1 \\
\hline Wald & $1.83(0.20)$ & $2.17(0.20)$ & $1.12(0.36)$ & $0.43(0.59)$ & $0.34(0.61)$ \\
\hline$U$ & 1.01 & 1.00 & 1.00 & 1.00 & 1.02 \\
\hline$M S E-T$ & $-0.56(0.43)$ & $0.10(0.25)$ & $-0.13(0.33)$ & $0.37(0.22)$ & $-1.18(0.70)$ \\
\hline MSE-F & $-1.56(0.84)$ & $0.20(0.20)$ & $-0.05(0.31)$ & $0.07(0.28)$ & $-2.31(0.92)$ \\
\hline$E N C-T$ & $-0.02(0.36)$ & $0.71(0.20)$ & $0.31(0.31)$ & $0.42(0.32)$ & $-0.96(0.70)$ \\
\hline ENC-NEW & $-0.03(0.38)$ & $0.70(0.12)$ & $0.06(0.34)$ & $0.04(0.40)$ & $-0.82(0.93)$ \\
\hline \multicolumn{6}{|l|}{ Term spread } \\
\hline$q_{1}$ & 12 & 12 & 6 & 3 & 1 \\
\hline$q_{2}$ & 3 & 1 & 1 & 2 & 1 \\
\hline Wald & $1.67(0.23)$ & $0.27(0.65)$ & $3.09(0.19)$ & $4.74(0.12)$ & $0.46(0.61)$ \\
\hline$U$ & 1.06 & 1.06 & 0.98 & 0.99 & 1.00 \\
\hline$M S E-T$ & $-2.38(0.99)$ & $-1.73(0.84)$ & $1.14(0.07)$ & $0.71(0.14)$ & $-0.50(0.46)$ \\
\hline$M S E-F$ & $-8.09(0.99)$ & $-7.66(0.97)$ & $\mathbf{2 . 5 6}(0.08)$ & $1.39(0.13)$ & $-0.53(0.44)$ \\
\hline$E N C-T$ & $-1.24(0.83)$ & $-1.34(0.79)$ & $1.24(0.13)$ & $0.96(0.20)$ & $-0.18(0.48)$ \\
\hline ENC-NEW & $-1.92(0.98)$ & $-2.70(0.97)$ & $1.54(0.14)$ & $1.00(0.20)$ & $-0.09(0.48)$ \\
\hline \multicolumn{6}{|c|}{ Dividend yield, first difference } \\
\hline$q_{1}$ & 12 & 12 & 6 & 3 & 0 \\
\hline$q_{2}$ & 1 & 1 & 1 & 1 & 1 \\
\hline Wald & $1.83(0.25)$ & $1.19(0.36)$ & $0.00(0.95)$ & $2.94(0.17)$ & $1.85(0.26)$ \\
\hline$U$ & 1.00 & 1.00 & 1.01 & 0.99 & 1.00 \\
\hline$M S E-T$ & $\mathbf{0 . 7 6}(0.09)$ & $0.15(0.22)$ & $-1.94(0.95)$ & $0.84(0.13)$ & $1.07(0.11)$ \\
\hline$M S E-F$ & $0.52(0.14)$ & $0.15(0.22)$ & $-0.88(0.70)$ & $\mathbf{0 . 9 5}(0.09)$ & $0.37(0.17)$ \\
\hline$E N C-T$ & $0.90(0.14)$ & $0.27(0.31)$ & $-1.80(0.95)$ & $0.91(0.21)$ & $1.11(0.19)$ \\
\hline ENC-NEW & $0.31(0.24)$ & $0.13(0.31)$ & $-0.40(0.81)$ & $0.52(0.15)$ & $0.20(0.26)$ \\
\hline \multicolumn{6}{|c|}{ Real effective exchange rate, first difference } \\
\hline$\overline{q_{1}}$ & 12 & 12 & 6 & 3 & 0 \\
\hline$q_{2}$ & 3 & 1 & 1 & 1 & 1 \\
\hline Wald & $2.49(0.18)$ & $2.86(0.16)$ & $0.14(0.74)$ & $0.45(0.60)$ & $2.05(0.26)$ \\
\hline$U$ & 1.03 & 1.02 & 1.01 & 1.01 & 1.00 \\
\hline$M S E-T$ & $-1.99(0.92)$ & $-1.47(0.80)$ & $-2.01(0.95)$ & $-1.37(0.77)$ & $-0.33(0.44)$ \\
\hline$M S E-F$ & $-4.60(0.97)$ & $-2.74(0.92)$ & $-0.86(0.69)$ & $-0.88(0.72)$ & $-0.33(0.55)$ \\
\hline$E N C-T$ & $-1.02(0.73)$ & $-0.54(0.57)$ & $-1.69(0.93)$ & $-1.06(0.75)$ & $0.26(0.38)$ \\
\hline ENC-NEW & $-1.13(0.94)$ & $-0.48(0.82)$ & $-0.35(0.76)$ & $-0.32(0.75)$ & $0.12(0.34)$ \\
\hline \multicolumn{6}{|c|}{ Real share price growth } \\
\hline$q_{1}$ & 12 & 12 & 6 & 3 & 1 \\
\hline$q_{2}$ & 1 & 1 & 1 & 1 & 1 \\
\hline Wald & $4.91(0.08)$ & $\mathbf{8 . 4 1}(0.01)$ & $1.72(0.26)$ & $4.19(0.10)$ & $3.45(0.15)$ \\
\hline$U$ & 0.99 & 0.98 & 1.00 & 0.99 & 0.99 \\
\hline$M S E-T$ & $1.08(0.04)$ & $\mathbf{0 . 7 5}(0.09)$ & $0.61(0.14)$ & $1.01(0.09)$ & $0.64(0.18)$ \\
\hline$M S E-F$ & $1.90(0.04)$ & $2.33(0.03)$ & $0.54(0.17)$ & $1.86(0.04)$ & $0.82(0.16)$ \\
\hline ENC-T & $\mathbf{1 . 5 5}(0.05)$ & $1.33(0.07)$ & $0.71(0.22)$ & $1.25(0.13)$ & $1.21(0.18)$ \\
\hline ENC-NEW & $1.40(0.08)$ & $2.33(0.03)$ & $0.33(0.25)$ & $\mathbf{0 . 2 3}(0.08)$ & $0.73(0.19)$ \\
\hline
\end{tabular}


Continued Table 1

\begin{tabular}{|c|c|c|c|c|c|}
\hline Horizon $(\mathrm{h})$ & 1 month & 3 months & 6 months & 9 months & 12 months \\
\hline \multicolumn{6}{|c|}{ Real non-food credit growth } \\
\hline$q_{1}$ & 12 & 12 & 6 & 3 & 1 \\
\hline$q_{2}$ & 1 & 1 & 1 & 1 & 1 \\
\hline Wald & $0.11(0.79)$ & $0.42(0.64)$ & $0.11(0.81)$ & $1.94(0.26)$ & $0.09(0.78)$ \\
\hline$U$ & 1.01 & 1.02 & 1.02 & 1.00 & 1.01 \\
\hline$M S E-T$ & $-1.09(0.69)$ & $-1.87(0.91)$ & $-1.16(0.68)$ & $0.43(0.17)$ & $-0.85(0.59)$ \\
\hline MSE-F & $-0.88(0.62)$ & $-2.27(0.84)$ & $-2.28(0.86)$ & $0.29(0.20)$ & $-1.11(0.75)$ \\
\hline$E N C-T$ & $-0.63(0.63)$ & $-1.44(0.90)$ & $-1.00(0.73)$ & $0.46(0.30)$ & $-0.64(0.62)$ \\
\hline ENC-NEW & $-0.25(0.63)$ & $-0.87(0.91)$ & $-0.99(0.92)$ & $0.15(0.32)$ & $-0.42(0.80)$ \\
\hline
\end{tabular}

Notes: The out-of-sample period is 2005:4-2011:4. $q_{1}$ and $q_{2}$ are the lags of the ARDL equation. Wald is computed using data over 1994:1-2011:4 period. Boot strapped p-values are given in parentheses. 0.00 signifies $<0.005$. Bold numbers indicate significance at the $10 \%$ level according to the bootstrapped $p$-values.

Table 2. Least squares estimations of $\lambda$

\begin{tabular}{|c|c|c|c|c|c|}
\hline $\operatorname{Horizon}(\mathrm{h})$ & 1 month & 3 months & 6 months & 9 months & 12 months \\
\hline \multicolumn{6}{|l|}{ Mogrowth } \\
\hline$\lambda$ & 0.9056 & 0.9124 & 0.2350 & 0.2124 & \\
\hline$U$ & 0.8891 & 0.8958 & 0.9507 & 0.9508 & \\
\hline \multicolumn{6}{|l|}{ M1growth } \\
\hline$\lambda$ & & 0.2614 & 0.1048 & 0.1044 & \\
\hline$U$ & & 0.9898 & 0.9542 & 0.9506 & \\
\hline \multicolumn{6}{|l|}{ M2growth } \\
\hline$\lambda$ & 0.9631 & 0.9688 & & & \\
\hline$U$ & 0.9645 & 0.9588 & & & \\
\hline \multicolumn{6}{|l|}{ M3growth } \\
\hline$\lambda$ & 0.9047 & 0.9450 & & & \\
\hline$U$ & 0.9691 & 0.9278 & & & \\
\hline \multicolumn{6}{|c|}{ Lending rate, first difference } \\
\hline$\lambda$ & 0.1745 & & & & \\
\hline$U$ & 0.9849 & & & & \\
\hline \multicolumn{6}{|c|}{ Real share price growth } \\
\hline$\lambda$ & 0.9493 & 0.9515 & & 0.9218 & \\
\hline$U$ & 0.9740 & 0.9763 & & 0.9458 & \\
\hline
\end{tabular}

Notes: $\lambda$ is the estimated weight attached to the unrestricted model out-of-sample forecast in an optimal composite out-of-sample forecast; the weight is estimated using a regression model with an intercept term. 


\subsection{Empirical results}

Table 1 presents forecasting test results for the four out-of-sample test statistics for Indian industrial production growth corresponding to the 11 financial variables at horizons 1, 3, 6, 9 and12 months over the 2005:4-2011:4 out-of-sample period. Table 1 further presents values of $q_{1}$ and $q_{2}$ determined by the SIC criterion, the in-sample Wald statistic and Theil's $U$. Following Rapach and Weber (2004), a bootstrap procedure is used to generate the p-values given in parentheses for the Wald and four out-of-sample statistics. We find evidence of insample forecasting power for M0, M1, M2, M3, the lending rate and real share price growth rate for at least one of the 5horizon-lengths considered. The strongest evidence is obtained for M0. Further, when compared to the existing literature, unlike Ray and Chatterjee (2001), we find that stock price, M3 and an interest rate variable (lending rate) do have in-sample predictability for output growth. Our results corroborate the findings for Ray and Chatterjee (2001) regarding the exchange rate, but fail to find in-sample predictability of non-food credit growth, unlike Kar and Mandal (2011).

When we move to the relative MSFE metric, we find that barring few cases (six-months, nine-months and twelve-months ahead forecast horizons for $\mathrm{M} 1$ and one-month ahead forecast horizon for the first-differenced lending rate), the value of the Theil's $U$ is less than one for all the cases where we found in-sample predictability. However, there are also three cases (six-months and nine-months ahead for the term-spread and nine-months ahead for the dividend yield), where the Theil's $U$ is less than one even when there is no in-sample predictability. Now, when we turn to the significance of the four out-of-sample statistics for the cases where in-sample and out-of-sample predictabilities coincide, we find that at least one of MSE-T, MSE-F, ENC-T and $E N C-N E W$ statistics are significant. In fact, barring the nine-months ahead horizon of the lending rate, for which the MSE-F statistic is significant at the 10 percent level, the most powerful of the out-of-sample statistics, namely ENC-NEW, is significant at least at the ten percent level for all the cases where the Theil's $U$ less than one, and there exists in-sample predictability. However, in the case of the nine-month ahead forecast resulting from the term-spread, where there is no in-sample predictability, but the Theil's $U$ is less than one, none of the forecast comparison statistics are significant. Also note that, for the two cases (six-months ahead for the term-spread and nine-months ahead for the dividend yield), where the Theil's $U$ value is less than one without any evidence of in-sample predictability, at least one of the weaker (MSE-T and $M S E-F$ ) out-of-sample test statistics are significant.

There are four interesting cases, namely, three-months, six-months and nine-months ahead forecast horizons for M1, and one-month ahead forecast horizon for the first-differenced lend ingrate, where the Theil's $U$ is greater than one, but out-of-sample predictability is obtained based on the ENC-NEW test statistic. Note that, for the case of three-months ahead forecast for M1, there is no evidence of in-sample predictability. At this stage, it is important to highlight what the ENC statistics mean, since it might seem counterintuitive to have out-of-sample forecasting ability from a specific variable, even when the Theil's $U$ exceeds one. Intuitively, the significance of the ENC statistics reflects the fact that the AR (restricted) model forecasts have little explanatory power for the ARDL (unrestricted) model forecast errors, so that the ARDL model forecasts must contain information not 
found in the AR model forecasts. That is, if the AR model forecast errors contain little information for predicting the ARDL errors, the AR model does not forecast encompass the ARDL model, even if the two model yield forecast errors with very similar variances. In addition, the ENC statistics are also likely to be significant when the AR and ARDL model forecast errors have strong negative correlation. In this case, AR model forecast errors of a given sign are associated with ARDL model forecast errors of the opposite sign, so that the optimal composite forecast should incorporate information from both the AR and ARDL models. In general, we find relatively strong evidence (based on the ENC-NEW statistics) of out-of-sample predictability for at least one of the horizons considered for M0, M1, M2, M3, the lending rate and real share price growth rate. The term-spread and dividend yield are added to the list when weaker versions of the outof-sample test statistics are considered as well. Overall, eight out of the eleven financial variables considered contain some form of out-of-sample predictability for the Indian industrial production growth rate.

Our results point to at least six financial variables, where, for at least one of the five out-of-sample horizons considered, we can reject the null hypothesis that forecasts of industrial production growth generated by a benchmark AR model encompass forecasts generated by a more general ARDL model that includes a financial variable. However, such tests of statistical significance fail to provide us information about by how much these financial variables improve forecasts, i.e. these tests do not inform us of economic significance of our results. Given this, Table 2 reports the estimated weight, $\lambda$, attached to the ARDL model forecast in forming the optimal composite forecast. We only consider the cases in Table 1, for which the ENC-T and/or the ENC-NEW statistics are significant at the 10 percent level. Following Granger and Ramanathan (1984), we report the estimates of $\lambda$ that are obtained with an intercept term included in Eq. (4). Note that, as $\lambda$ increases the unrestricted model forecast is relatively more important in generating the optimal composite forecast. Though all the estimates of $\lambda$ are significant at the 10 percent level, as is known from Table 1, its estimates vary considerably in Table 2. Barring the equations involving $M 1$ growth, the first-difference of the lending rate, and longer horizons of M0 growth, where the values of $\lambda$ lie between 0.1044 to 0.2614 , the other estimated values of $\lambda$ are exceptionally high and all over 0.9056 . In the latter cases, forecasts formed from using the ARDL model, i.e. including financial variables, play a quantitatively important role in generating the optimal composite of the growth rate of the Indian industrial production. Also in number of cases, as can be seen from the $U$ measures reported in Table 2, there is considerable reduction in the relative MSFE for the optimal composite forecasts relative to the benchmark AR forecasts.

In Figure 2, we analysed the ability of the 11 financial variables in predicting the turning points of the growth rate of industrial production over the seventy-three months out-of-sample period of 2005:4 to 2011:4. In this regard, we plot the one-step-ahead forecasts obtained from the recursive estimation of the AR and the 11 individual ARDL models over the outof-sample period. The recursive scheme allows us to simulate the situation of a forecaster in real time. As can be seen from Figure 2, all the financial variables tend to behave similarly in predicting the turning points of the growth rate of industrial production. And, in general, 

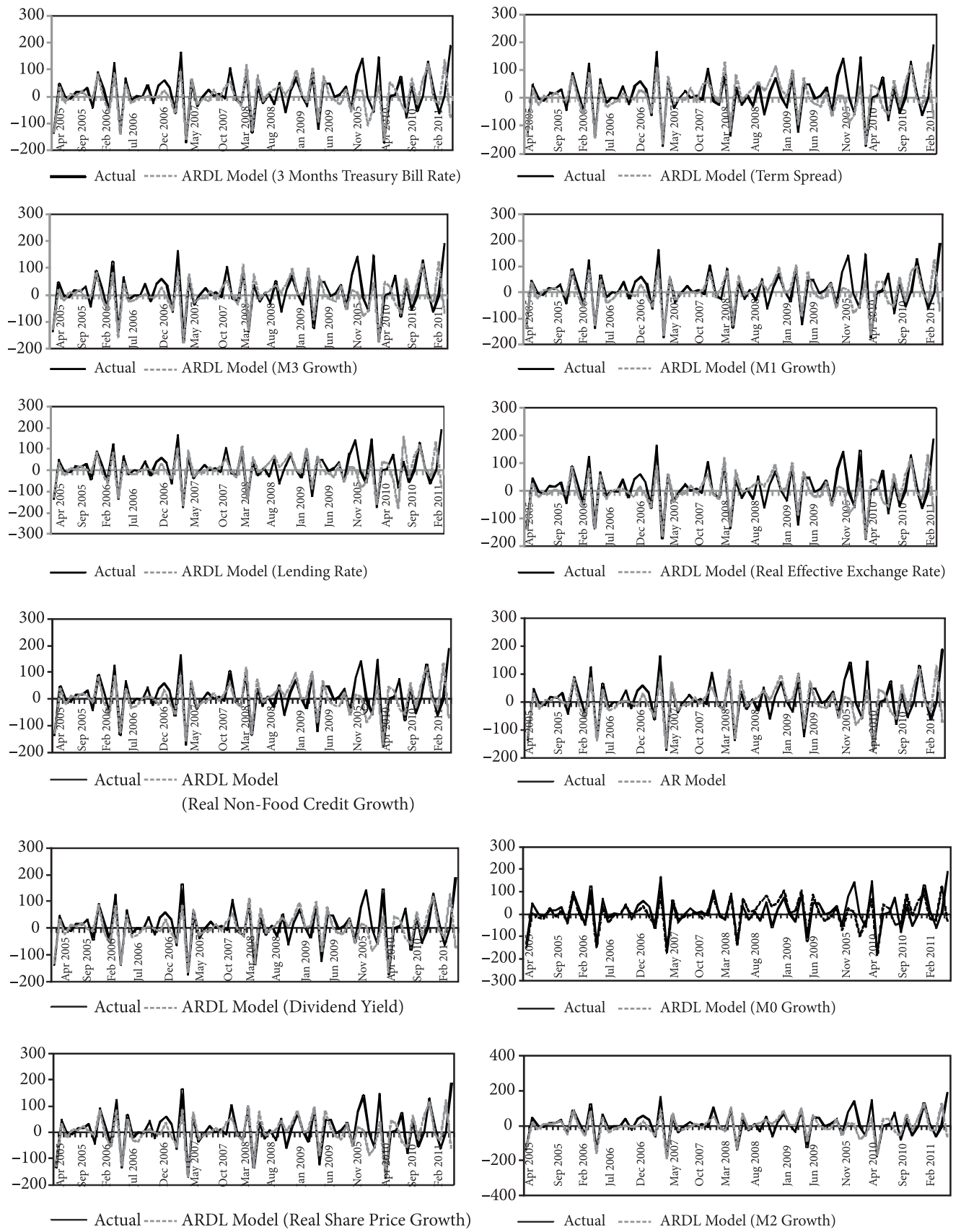

Fig. 2. Out-of-sample one-step-ahead recursive forecast plots (2005:4-2011:4) 
barring the end of the sample where the AR and ARDL models predicted a slowdown in the growth rate of the industrial production when the same actually witnessed an increase in the growth rate, all the models perform equally well for the other turning points. In sum, it is difficult to differentiate between the role played by the individual financial variables relative to each other and also the AR model based on the turning point exercise.

We have indicated that majority of the 11 financial variables considered evince ability to forecast and predict the turning points of industrial production growth over the out-of-sample period of 2005:4-2011:4. But, given that we consider a large number of financial variables, it is fair to wonder, as suggested by Gupta and Modise (2012), if our significant results reported in Table 1 are due to data mining across the 11 financial variables, even though it is believed that out-of-sample tests are, in general, immune to data mining. Inoue and Kilian (2005), however, suggest that both in-sample and out-of-sample tests are equally susceptible to data mining. For this reason, we implement a version of the data-mining bootstrap procedure developed by Inoue and Kilian (2005). In our case, the null hypothesis posits that none of the 11 financial variables considered has out-of-sample predictive ability over the out-of-sample period, with the alternative hypothesis being that at least one of the financial variables has forecasting power over the out-of-sample. Inoue and Kilian (2005) recommend using the maximal out-ofsample test statistic to implement this test, whereby we test the null hypothesis that the largest specific out-of-sample test statistic (MSE-T, MSE-F, ENC-T or ENC-NEW) concerned for the 11 financial variables is equal to zero against the alternative that the same is greater than zero. Table 3 reports the data-mining-robust critical values corresponding to Table 1 for the out-ofsample period forecasting exercise of the industrial production growth rate. Given the ranking of the out-of-sample test statistics, we are most interested in checking whether the significant ENC-T and ENC-NEW tests reported in Table 1, continue to remain significant after we use data-mining-robust critical values. Comparing the results in Table 1 with that of Table 3, it is clear that a majority of our positive out-of-sample results suffer from data mining. As can now be seen, only M0 (one-month, three-months, six-months and nine-months), M1 (six-months) and M2 (one-month) retain some of its predictive ability with respect to industrial production. Three-months ahead forecasts from M2and M3 is added to this list, if we consider the relatively weaker MSE-T statistic. Interestingly, the forecasting ability of the real stock price growth rate completely disappears. Our results, thus, highlight the importance of accounting for data mining, since if ignored, one could be led to falsely over emphasizing the ability of financial variables in predicting the growth rate of Indian industrial production.

Table 3. Data-mining-robust boot strap critical values for the maximal out-of-sample statistic

\begin{tabular}{|c|c|c|c|c|c|c|c|c|c|c|c|c|c|c|c|}
\hline \multirow{2}{*}{$\begin{array}{l}\text { Horizon } \\
\quad(h) \\
\text { Sig. } \\
\text { Level }\end{array}$} & \multicolumn{3}{|c|}{1 month } & \multicolumn{3}{|c|}{3 months } & \multicolumn{3}{|c|}{6 months } & \multicolumn{3}{|c|}{9 months } & \multicolumn{3}{|c|}{12 months } \\
\hline & $10 \%$ & \% & $1 \%$ & $10 \%$ & $5 \%$ & $1 \%$ & $10 \%$ & $5 \%$ & $1 \%$ & $10 \%$ & $5 \%$ & $1 \%$ & $10 \%$ & $5 \%$ & $1 \%$ \\
\hline$M S E-T$ & 1.64 & 1.88 & 2.28 & 1.85 & 2.21 & 2.76 & 2.29 & 2.56 & 3.11 & 2.49 & 2.72 & 3.39 & 2.85 & 3.28 & 4.04 \\
\hline$M S E-F$ & 3.42 & 4.45 & 6.48 & 3.68 & 4.64 & 7.26 & 4.14 & 5.62 & 11.13 & 5.46 & 8.12 & 12.42 & 5.41 & 6.90 & 12.20 \\
\hline ENC-T & 2.22 & 2.44 & 2.77 & 2.40 & 2.67 & 3.74 & 2.83 & 3.10 & 3.78 & 3.11 & 3.46 & 4.92 & 3.60 & 4.18 & 5.54 \\
\hline $\begin{array}{l}E N C- \\
N E W\end{array}$ & 3.44 & 4.55 & 6.60 & 3.56 & 4.96 & 7.33 & 4.26 & 6.14 & 10.86 & 5.60 & 9.06 & 6.79 & 4.70 & 7.00 & 8 \\
\hline
\end{tabular}




\section{Conclusions}

The little evidence, at times conflicting, that exists regarding the role of financial variables in forecasting Indian output growth is mainly in-sample. Against this backdrop, we consider the forecasting power, both in- and out-of-sample, of 11 financial variables with respect to Indian industrial production growth rate over the monthly out-of-sample period of 2005:4-2011:4, using an in-sample of 1994:1-2005:3. The financial variables used in this study, namely, M0, M1, M2, M3, lending rate, 3-month Treasury bill rate, term spread, real effective exchange rate, real stock prices, dividend yield and non-food credit growth, are quite popular in the extant literature. We observe strong evidence of out-of-sample predictability for at least one of the horizons for M0, M1, M2, M3, the lending rate and real share price growth rate. The termspread and dividend yield are added to the list when weaker versions of the out-of-sample test statistics are considered as well. We also observe that, at times, in-sample and out-of-sample predictive ability of the financial variables tend to coincide. Given that we consider a large number of financial variables, when we checked the significant results by accounting for data mining across the 11 financial variables, majority of these results are found not to be robust to data mining. Once, we control for data mining only M0, M1 and M2 retain some of its predictive ability. In light of this result of limited predictability of the Indian output growth based on financial variables in a linear framework, future research would aim to analyse the same in a non-linear framework along the lines of Peel and Paya (2004).

\section{Acknowledgements}

We would like to thank three anonymous referees for many helpful comments. Any remaining errors are, however, solely ours. We are also indebted to the Editor, Professor Saparauskas, for extending our deadline to revise the paper.

\section{References}

Beck, N.; King, G.; Zeng, L. 2000. Improving quantitative studies of international conflict: a conjecture, American Political Science Review 94(1): 21-26. http://dx.doi.org/10.2307/2586378

Beck, N.; King, G.; Zeng, L. 2004. Theory and evidence in international conflict: a response to de Marchi, Gelpi, and Grynaviski, American Political Science Review 98(2): 379-389. http://dx.doi.org/10.1017/S0003055404001212

Bhattacharya, R.; Pandey, R.; Veronese, G. 2011. Tracking India growth in real time, Working paper, National Institute of Public Finance and Policy, New Delhi.

Biswas, D.; Singh, S.; Sinha, A. 2010. Forecasting inflation and IIP growth: Bayesian vector autoregressive model, Reserve Bank of India Occasional Papers 31(2): 31-48.

Bruno, G.; Lupi, C. 2004. Forecasting industrial production and the early detection of turning points, Empirical Economics 29(3): 647-671. http://dx.doi.org/10.1007/s00181-004-0203-y

Clark, T. E.; McCracken, M. W. 2001. Tests of equal forecast accuracy and forecast encompassing for nested models, Journal of Econometrics 105(1): 85-110. http://dx.doi.org/10.1016/S0304-4076(01)00071-9

Clark, T. E.; McCracken, M. W. 2004. Evaluating long-horizon forecasts. University of Missouri-Columbia Manuscript. 
Clark, T. E.; McCracken, M. W. 2005. Evaluating direct multistep forecasts. Econometric Reviews 24(4): 369-404. http://dx.doi.org/10.1080/07474930500405683

Clements, M.; Hendry, D. 1998. Forecasting economic time series. New York: Cambridge University Press. 368 p. http://dx.doi.org/10.1017/CBO9780511599286

Diebold, F.; Mariano, R. 1995. Comparing predictive accuracy, Journal of Business and Economic Statistics 13(2): 253-265. http://dx.doi.org/10.2307/1392185

Espinoza, R.; Fornari, F.; Lombardi, M. J. 2012. The role of financial variables in predicting economic activity, Journal of Forecasting 31(1): 15-46. http://dx.doi.org/10.1002/for.1212

Granger, C. W. J.; Ramanathan, R. 1984. Improved methods of forecasting, Journal of Forecasting 3(2): 197-204. http://dx.doi.org/10.1002/for.3980030207

Gupta, R.; Modise, M. P. 2012. South African stock return predictability in the context data mining: the role of financial variables and international stock returns, Economic Modelling 29(3): 908-916. http://dx.doi.org/10.1016/j.econmod.2011.12.013

Harvey, D.; Leybourne, S.; Newbold, P. 1998. Tests for forecast encompassing, Journal of Business and Economic Statistics 16(2): 254-259. http://dx.doi.org/10.2307/1392581

Inoue, A.; Kilian, L. 2005. In-sample or out-of-sample tests of predictability: which one should we use?, Econometric Reviews 23(4): 371-402. http://dx.doi.org/10.1081/ETC-200040785

Kar, S.; Mandal, K.; 2011. Banks, stock markets and output: interactions in the Indian economy, in GDN 12th Annual Global Development Conference, 13-15 January, 2011, Colombia.

Kilian, L. 1999. Exchange rates and monetary fundamentals: what do we learn from long-horizon regressions?, Journal of Applied Econometrics 14(5): 491-510. http://dx.doi.org/10.1002/(SICI)1099-1255(199909/10)14:5<491::AID-JAE527>3.0.CO;2-D

McCracken, M. 2004. Asymptotics for out-of-sample tests of granger causality, Manuscript, University of Missouri at Columbia.

Newey, W.; West, K. 1987. A simple, positive semi-definite, heteroskedasticity and autocorrelation consistent convariance matrix, Econometrica 55(3): 703-708. http://dx.doi.org/10.2307/1913610

Peel, D.; Paya, I. 2004. Asymmetry in the link between the yield spread and industrial production: threshold effects and forecasting, Journal of Forecasting 23(5): 373-384. http://dx.doi.org/10.1002/for.921

Rapach, D. E.; Weber, C. E. 2004. Financial variables and the simulated out-of-sample forecastability of U.S. output growth since 1985: an encompassing approach, Economic Inquiry 42(4): 717-738. http://dx.doi.org/10.1093/ei/cbh092

Rapach, D. E.; Wohar, M. E.; Rangvid, J. 2005. Macro variables and international stock return predictability, International Journal of Forecasting 21(1): 137-166. http://dx.doi.org/10.1016/j.ijforecast.2004.05.004

Rapach, D. E.; Wohar, M. E. 2006. In-sample vs. out-of-sample tests of stock return predictability in the context of data mining, Journal of Empirical Finance 13(2): 231-247. http://dx.doi.org/10.1016/j.jempfin.2005.08.001

Rapach, D. E.; Strauss, J. K.; Zhou, G. 2009. Differences in housing price forecastability across U.S. states, International Journal of Forecasting 25(2): 351-372. http://dx.doi.org/10.1016/j.ijforecast.2009.01.009

Rapach, D. E.; Strauss, J. K. 2010. Bagging or combining (or both)? An analysis based on forecasting U.S. employment growth, Econometric Reviews 29(5): 511-533. http://dx.doi.org/10.1080/07474938.2010.481550

Rapach, D. E.; Strauss, J. K.; Zhou, G. 2010. Out-of-sample equity premium prediction: combination forecasts and links to the real economy, Review of Financial Studies 23(2): 821-862. http://dx.doi.org/10.1093/rfs/hhp063

Rapach, D. E.; Strauss, J. K. 2012. Forecasting U.S. state-level employment growth: an amalgamation approach, International Journal of Forecasting 28(2): 315-327.

http://dx.doi.org/10.1016/j.ijforecast.2011.08.004 
Ray, P.; Chatterjee, J. S. 2001. The role of asset prices in Indian inflation in recent years: some conjectures, Modelling Aspects of the Inflation Process and the Monetary Transmission Mechanism in Emerging Market Countries 8: 131-150.

Rossi, B.; Sekhposyan, T. 2010. Have economic models forecasting performance for US output growth and inflation changed over time, and when?, International Journal of Forecasting 26(4): 808-835. http://dx.doi.org/10.1016/j.ijforecast.2009.08.004

Stock, J.; Watson, M. 2003. Forecasting output and inflation: the role of asset prices, Journal of Economic Literature 41(3): 788-829. http://dx.doi.org/10.1257/002205103322436197

West, K. 1996. Asymptotic inference about predictive ability, Econometrica 64(5): 1067-1084. http://dx.doi.org/10.2307/2171956

Rangan GUPTA. Doctor, Professor at the Department of Economics, University of Pretoria. First degree in Economics, Calcutta University (1997); Master of Science (1999); Doctor (2005). Author of about 130 scientific articles. Research interests include macroeconomics and time series econometrics.

Yuxiang YE. She is a PhD candidate in Economics at the Department of Economics, University of Pretoria.

Christopher SAKO. He is a PhD candidate in Economics at the Department of Economics, University of Pretoria. 